
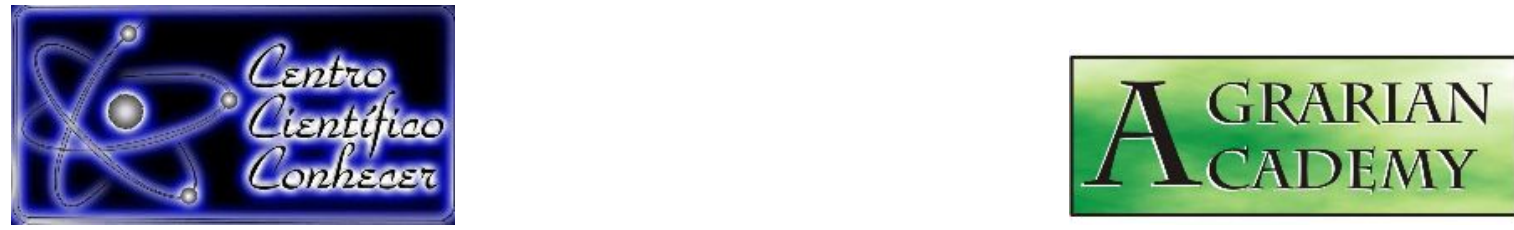

\title{
DIFERENTES SUBSTRATOS ORGÂNICOS NA PRODUÇÃO DE MUDAS DE BERINJELA NA AMAZÔNIA OCIDENTAL
}

Marina Conceição do Carmo ${ }^{1}$, Weverton Peroni dos Santos ${ }^{1}$, Caio Bastos Machado $^{1,}$ Marta Raiara Gomes Santos ${ }^{1}$, Núbia Pinto Bravin ${ }^{1}$

Graduandos (as) em agronomia pela Fundação Universidade Federal de

Rondônia - UNIR, Rolim de Moura - RO, Brasil. E-mail:

agrobiologia2@hotmail.com; wevertonperonisantos@gmail.com.

Recebido em: 14/07/2018 - Aprovado em: 28/07/2018 - Publicado em: 31/07/2018

DOI: 10.18677/Agrarian_Academy_2018a19

RESUMO

O bom desenvolvimento das mudas é imprescindível para a alta produtividade no campo, sendo o substrato o principal responsável por isso. O objetivo deste trabalho foi avaliar o desenvolvimento inicial da berinjela em função de substratos contendo diferentes fontes de matéria orgânica. A semeadura foi feita em sacos de polietileno de $500 \mathrm{~cm}^{3}$. Contendo as seguintes misturas $\mathrm{T} 1=$ solo puro (tratamento controle); $\mathrm{T} 2$ = solo + cama de frango $(1: 1 \mathrm{v} / \mathrm{v}) ; \mathrm{T} 3=$ solo + palha de café $(1: 1 \mathrm{v} / \mathrm{v}) ; \mathrm{T} 4=$ solo + cama de frango + palha de café $(1: 1: 1 \mathrm{v} / \mathrm{v})$. O delineamento experimental foi inteiramente casualizado, com 4 tratamentos e 6 repetições. Após 34 dias de semeadura, avaliaram-se à altura das plantas, diâmetro do caule, número de folhas, área foliar, comprimento de raiz e matéria seca total. Os tratamentos com os substratos T2 e T4 apresentaram resultados superiores aos demais para todos os parâmetros avaliados, exceto o número de folhas.

PALAVRAS- CHAVE: esterco de aves, palha de café, Solanum melogena L.

\section{DIFFERENT ORGANIC SUBSTRATES IN THE PRODUCTION OF EGGPLANT SEEDLINGS IN THE WESTERN AMAZON}

\begin{abstract}
The good development of the seedlings is essential for the high productivity in the field, and the substrate is mainly responsible for this. The objective of this work was to evaluate the initial development of the eggplant as a function of substrates containing different sources of organic matter. Seeding was done in polyethylene bags of $500 \mathrm{~cm}^{3}$. Containing the following mixtures $T 1=$ pure soil (control treatment); $\mathrm{T} 2=$ soil + chicken bed $(1: 1 \mathrm{v} / \mathrm{v}) ; \mathrm{T} 3=$ soil + coffee straw $(1: 1 \mathrm{v} / \mathrm{v}) ; \mathrm{T} 4=$ soil + chicken bed + coffee straw (1: $1: 1 \mathrm{v} / \mathrm{v})$. The experimental design was completely randomized, with 4 treatments and 6 replicates. After 34 days of sowing, plant height, stalk diameter, leaf number, leaf area, root length and total dry matter were evaluated. The treatments with the substrates T2 and T4 presented superior results to the others for all the evaluated parameters, except the number of leaves.
\end{abstract}

KEYWORDS: poultry manure, coffee straw, Solanum melogena L. 


\section{INTRODUÇÃO}

A berinjela é uma hortaliça que vem se difundido positivamente, o Brasil tem área cultivada de aproximadamente 837 mil hectares e volume de produção em torno de 63 milhões de toneladas, sendo contemplada na produção de hortaliças centenas de espécies cultivadas em todas as regiões do país (SABIO et al., 2016).

A produção de mudas constitui uma das fases mais importante na produção de hortaliças, o que vai impactar diretamente no campo. A utilização de substratos orgânicos vem crescendo devido à escassez de recursos e ao seu baixo custo, uma vez que esses podem estar disponíveis na propriedade ou suas proximidades (SEDIYAMA et al., 2014).

Os substratos orgânicos podem atender plenamente a demanda nutricional, esses compostos devem possuir boas propriedades físicas, químicas e biológicas compatíveis com a muda a ser produzida, além de não favorecer o desenvolvimento de doenças e plantas daninhas. Uma importante característica é a capacidade de reter a umidade e drenar o excesso de água (LIMA et al., 2006; LEAL et al., 2007; MOREIRA et al., 2010).

Dentre esses substratos um dos mais abundantes é a cama de frango e a palha de café, importantes resíduos da indústria aviária e cafeeira. A cama de frango possui quantidade suficiente de nutrientes para substituir ou complementar a adubação química (SANTOS et al., 2014). A palha de café é grande fonte de potássio e nitrogênio, além de ser uma excelente fonte de matéria orgânica, torna-se um ótimo substrato quando associada a outros compostos (NASCIMENTO et al., 2015). Objetivou-se neste trabalho avaliar o desenvolvimento inicial de mudas de berinjela em função de substratos contendo diferentes fontes de matéria orgânica.

\section{MATERIAL E MÉTODOS}

O experimento com as mudas de berinjela (Solanum melongena L.) foi conduzido no município de Rolim de Moura (RO), na fazenda experimental pertencente à Fundação Universidade Federal de Rondônia - UNIR, localizado no km 15 da Rodovia 479, lado norte (Latitude 1134'57" S e Longitude 6146'21" W; altitude de $277 \mathrm{~m}$ acima do mar).

O delineamento experimental adotado foi o inteiramente casualizado com quatro tratamentos e seis repetições, totalizando vinte e quatro unidades experimentais, sendo cada unidade composta por quatro plantas e 96 plantas em todo o experimento. Os tratamentos foram compostos pelo preparo dos substratos baseado na mistura de solo com as respectivas fontes matéria orgânica: $T_{1}=$ solo puro (tratamento controle); $\mathrm{T}_{2}$ = solo + cama de frango (1:1 v/v); $\mathrm{T}_{3}=$ solo + palha de café $(1: 1 \mathrm{v} / \mathrm{v}) ; T_{4}=$ solo + cama de frango + palha de café $(1: 1: 1 \mathrm{v} / \mathrm{v})$.

O solo utilizado para as misturas dos substratos é classificado como Latossolo Vermelho-Amarelo distrófico (EMBRAPA, 2013) com as seguintes características químicas: $\mathrm{pH}$ em $\mathrm{H}_{2} \mathrm{O} 6,44 ; \mathrm{M} . \mathrm{O} 8,36 \mathrm{~g} \mathrm{dm}^{-3}$; $\mathrm{P} 1,11 \mathrm{mg} \mathrm{dm}^{-3}$; $\mathrm{Na} 0,07$

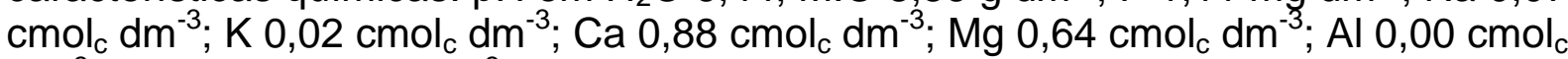
$\mathrm{dm}^{-3} ; \mathrm{H}+\mathrm{Al} 3,63 \mathrm{cmol}_{\mathrm{c}} \mathrm{dm}^{-3}$; Arg. 21,0\%; Areia 43,88\%.

As mudas foram produzidas em casa de vegetação no período de setembro a outubro de 2017. O substrato foi comportado em sacos de polietileno com as dimensões de $12 \times 22 \mathrm{~cm}$ e um volume de $500 \mathrm{~cm}^{3}$. Foi semeado em cada recipiente duas sementes do híbrido Classic F1 e o desbaste realizado 10 DAE (dias após emergência) deixando-se apenas a planta mais vigorosa em cada unidade. As 
plantas foram irrigadas diariamente, repondo um volume de água suficiente para elevar à umidade do substrato próximo a capacidade de campo.

Aos 30 DAE as mudas foram coletadas e acondicionadas em embalagens devidamente identificadas de acordo com cada tratamento, sendo posteriormente encaminhadas ao laboratório, onde foram avaliados os seguintes caracteres morfológicos: a) altura de planta - ALT (cm), b) diâmetro do caule - DC (mm), c) número de folhas por planta - NFP, d) área foliar - AFP $\left(\mathrm{cm}^{2}\right.$ planta $\left.{ }^{-1}\right)$, e) comprimento de raiz (cm) e f) massa seca total - MST (g. planta ${ }^{-1}$ ).

A altura foi mensurada com o auxílio de uma régua graduada em centímetros, medindo-se a partir do colo ao ápice da muda. O diâmetro do caule foi medido no colo da planta com o auxílio de um paquímetro. O Número de folhas por planta foi quantificado visualmente considerando-se apenas as folhas ativas. $\mathrm{Na}$ determinação da área foliar foram medidos: o maior comprimento longitudinal e transversal, segundo a metodologia descrita por Hinnah et al., (2014). O comprimento de raiz foi obtido medindo-se a partir do colo ao ápice da raiz logo após a lavagem cuidadosa do sistema radicular. Para determinação da matéria seca total (g planta ${ }^{-1}$ ), as plantas foram acondicionadas em sacos de papel e secas em estufa de circulação de ar forçada, a uma temperatura de $65 \mathrm{C}^{\circ}$ até atingir peso constante, logo após a retirada da estufa o material vegetal foi submetido à pesagem final em balança analítica de precisão.

Os dados obtidos foram submetidos à análise de variância pelo teste $\mathrm{F} e$ aplicados ao teste de Tukey a $5 \%$ de probabilidade para comparação das médias, com o uso do programa estatístico ASSISTAT (SILVA; AZEVEDO, 2016).

\section{RESULTADOS E DISCUSSÃO}

Como observado na tabela 1 não houve resultado significativo para a variável número de folhas por planta em nenhum dos tratamentos, no entanto todas as mudas apresentaram folhas em quantidade suficientes para o transplantio ( $>4)$, esse resultado se confirmam com o de Steffen et al., (2010), utilizando vermicomposto na produção de mudas de tomate, não verificando diferença nessa variável, observaram que o NFP por planta varia de 4 a 5 .

TABELA 1. Altura de planta - ALT (cm); diâmetro do caule - DC (mm); número de folhas por planta - NFP; área foliar - AFP $\left(\mathrm{cm}^{2}\right.$ planta $\left.{ }^{-1}\right)$; comprimento de raiz - CR (cm) e massa seca total - MST (g. planta $^{-1}$ ) sob o uso de diferentes substratos orgânicos. Rolim de Moura - RO. 2017.

\begin{tabular}{crrrrrr}
\hline Substrato & ALT & \multicolumn{1}{c}{ DC } & NFP & AFP & \multicolumn{1}{c}{ CR } & MST \\
\hline T1 & $7,5 \mathrm{~b}$ & $6,0 \mathrm{~b}$ & $4,3 \mathrm{a}$ & $23,1 \mathrm{~b}$ & $8,0 \mathrm{~b}$ & $0,05 \mathrm{~b}$ \\
T2 & $13,0 \mathrm{a}$ & $14,0 \mathrm{a}$ & $5,0 \mathrm{a}$ & $58,7 \mathrm{a}$ & $13,5 \mathrm{a}$ & $0,9 \mathrm{a}$ \\
T3 & $8,1 \mathrm{~b}$ & $6,5 \mathrm{~b}$ & $4,6 \mathrm{a}$ & $24,1 \mathrm{~b}$ & $8,7 \mathrm{~b}$ & $0,1 \mathrm{~b}$ \\
T4 & $13,4 \mathrm{a}$ & $14,6 \mathrm{a}$ & $5,5 \mathrm{a}$ & $60,3 \mathrm{a}$ & $14,5 \mathrm{a}$ & $0,9 \mathrm{a}$ \\
\hline CV\% & 19.42 & 25.08 & 14.64 & 33.19 & 16.90 & 26.01
\end{tabular}

Letras minúsculas iguais na coluna não diferem pelo teste de Tukey ao nível de $5 \%$ de probabilidade. $\mathrm{T}_{1}=$ solo puro (tratamento controle) $; \mathrm{T}_{2}=$ solo + cama de frango; $\mathrm{T}_{3}=$ solo + palha de café $\mathrm{T}_{4}=$ solo + cama de frango + palha de café

Apesar da não variação da NFP, os tratamentos com associação de cama de frango + solo e solo + cama de frango + palha de café, apresentaram área foliar superiores aos demais tratamentos (tabela 1) isto ocorreu devido a maior disponibilidade de nutriente facilitando a expansão celular. A área foliar é um AGRARIAN ACADEMY, Centro Científico Conhecer - Goiânia, v.5, n.9; p. 1902018 
parâmetro tão importante quanto o número de folhas para o transplantio, refletindo na capacidade da planta em interceptar radiações e fazer trocas gasosas, tornandose um importante indicativo de rendimento das culturas (FIGUEIREDO et al., 2010).

Para a variável matéria seca total (tabela 1), verificou-se que os melhores resultados obtidos foram nos tratamentos T2 e T4. Esse resultado confirma as aferições feitas nas demais variáveis, segundo Medeiros et al., (2013), é possível verificar qual substrato forneceu mais nutrientes através da matéria seca das mudas. Santos et al., (2014) também observaram maior incremento de material seco em mudas de cupuaçuzeiro em substratos com cama de frango.

$\mathrm{Na}$ tabela 1, nota-se que houve efeito significativo entre os tratamentos para a variável morfológica altura, sendo os tratamentos; T2 e T4 os que proporcionaram maior altura das mudas de berinjela em relação aos demais tratamentos com substratos, e não diferiram entre si. Os substratos fornecem porosidade e aeração o que contribui para o maior desenvolvimento em altura, e quanto maior for essa característica nos substratos, menor será o gasto que as plantas terão para se ramificar, investindo mais no crescimento em altura (SUGUINO et al., 2001).

Segundo Lima et al., (2006) a cama de aviário mostra-se uma boa fonte de energia para as plantas, além de propiciar condições físicas e químicas mais adequadas para o desenvolvimento das mudas, principalmente quando combinada com outros materiais orgânicos. Resultados contrários foram obtidos por Kreft et al., (2017) que ao observarem o desenvolvimento de mudas de Bauhinia variegata L. e Ceiba speciosa, verificaram que o uso desse tipo de substrato não influenciou de maneira significativa na altura das plantas.

Para a variável diâmetro do caule (tabela 1), verificou-se significância nos resultados, sendo os tratamentos solo + cama de frango (T2) e solo + cama de frango + palha de café (T4) os que proporcionaram os melhores diâmetro das mudas em relação aos demais tratamentos e não diferiram entre si. Trazzi et al., (2013) trabalhando com mudas de teca (Tectona grandis) verificaram que o maior diâmetro de caule foi obtido usando substrato composto com 35\% de cama de aviário. Frade Junior et al., (2011), obtiveram maiores valores no diâmetro de mudas de ingazeiro (Inga edulis Mart.) utilizando substratos contendo 20\% de cama de aviário.

O diâmetro obtido neste trabalho foi proporcional à altura da planta, ou seja, quanto maior o diâmetro maior foi à altura obtida, sendo que os tratamentos T2 e T4 não diferiram entre si. Assim como o diâmetro, o comprimento das raízes foi condizente as demais variáveis, apresentando resultados superiores nos tratamentos T2 e T4.

Observa-se ainda (tabela 1) que as mudas que apresentaram os menores valores para o crescimento em altura, diâmetro de caule, área foliar, comprimento de raiz e massa seca, foram verificados aquelas produzidas em substrato com solo + palha de café (T3) e solo puro (T1), tal resultado deve-se ao menor teor de matéria orgânica presente no substrato, quando comparado aos demais substratos avaliados, o que implica em uma menor capacidade de fornecer as condições físicas (estrutura) e químicas (nutrientes) adequadas, comprometendo dessa forma o crescimento e desenvolvimentos das mudas de berinjelas.

Carmo et al., (2018) avaliando o desenvolvimento de mudas de jiloeiro sob o uso de diferentes substratos, observaram menores valores em todas as variáveis estudadas quando utilizado o substrato composto de solo puro, o que afetou todo o desenvolvimento da planta devido suas limitações nutricionais.

Comparando-se o desenvolvimento das mudas entre os tratamentos que receberam substrato orgânico (T2 e T4, exceto T3) com as plantas cultivadas 
apenas no solo, observa-se a importância da adubação orgânica para o desenvolvimento inicial de mudas de berinjela, principalmente na região da zona da mata - RO, visto que grande parte dos produtores não realizam a adubação química, tornando-se, portanto, viável o uso de substratos orgânicos que além dos benefícios o uso é de baixo custo, uma vez que podem estar disponíveis na propriedade ou em suas proximidades.

\section{CONCLUSÕES}

Os substratos T2 + T4 foram os que proporcionaram os melhores resultados para o desenvolvimento morfológico de mudas de berinjela. Exceto para variável número de folhas que não foi afetado pelo uso dos diferentes substratos.

Observou-se que a utilização dos substratos orgânicos foi viável para suprir as necessidades de desenvolvimento das mudas, além de ser um material de baixo custo. Através das análises morfológicas ao final do estudo, as mudas apresentaram aptidão para serem transplantadas a campo.

\section{REFERÊNCIAS}

CARMO, C. M. do.; CUNICO, M. J.; SILVA, M. K. P. da.; MACHADO, B.C. de. CARMO, C. G. do. Compostagem e borra de café como substrato na produção de mudas de jiló. Enciclopédia Biosfera, v.15 n.27; p. 2018. Disponível em: DOl: 10.18677/EnciBio_2018A30.

EMBRAPA - Empresa Brasileira de Pesquisa Agropecuária. Sistema brasileiro de classificação de solos. 3. ed. Brasília: Embrapa; 2013. Disponível em: < http://livimagens.sct.embrapa.br/amostras/00053080.pdf> Acesso em: 02 jul. 2018.

FIGUEIREDO, R. T.; GUISCEM, J. M.; CHAVES, A. M. S.; AGUIAR JUNIOR, R. A.; SILVA, A. G. P.; PAIVA, J. B. P.; SANTOS, F. N. Relação entre a área foliar, número de folhas e biomassa seca e fresca da planta de rúcula. Horticultura brasileira, v.

28, $\quad$ n. 2 2. 2010. Disponível em: http://www.abhorticultura.com.br/eventosx/trabalhos/ev_4/A2963_T4554_Comp.pdf> Acesso em: 25 mai. 2018.

FRADE JUNIOR, E. F.; ARAÚJO, J. A.; SILVA, S. B.; MOREIRA, J. G. V.; SOUZA, L. P. Substratos de resíduos orgânicos para produção de mudas de ingazeiro (Inga edulis Mart) no vale do Juruá - Acre. Enciclopédia Biosfera, v.7, n.13; p.959-969, $2011 . \quad$ Disponível em: $<$ http://www.conhecer.org.br/enciclop/2011b/ciencias\%20agrarias/substratos\%20de \%20residuos.pdf> Acesso em: 04 jun. 2018.

HINNAH, F. D.; HELDWEIN, A. B.; MALDANER, I. C.; LOOSE, L. H.; LUCAS, D. D. P.; BORTOLUZZI, M. P. Estimativa de área foliar de berinjela em função das dimensões foliares. Bragantia, v. 73, n. 3, p.213-218, 2014. Disponível em: http://dx.doi.org/10.1590/1678-4499.0083.

KREFT, S. M.; BRUN, E. J.; FACCHI, S. P.; SANTOS, L. M.; KLEIN, D. R.; KREFTA, S. C.; GERMANO, A. D.; FRIGERI, J. V. Desenvolvimento inicial de mudas de Bauhinia variegata L. e Ceiba speciosa (A. St. Hil.) Ravenna em substratos à base de cama de aviário. Scientia Agraria Paranaensis, v. 16, n. 1, p. 99-106, 2017. Disponível em: http://dx.doi.org/10.18188/1983-1471/sap.v16n1p99-68. 
LEAL M. A. A. de.; GUERRA J. G. M.; PEIXOTO R. T. G.; ALMEIDA D. L. Utilização de compostos orgânicos como substratos na produção de mudas de hortaliças. Horticultura Brasileira, v. 25, n. 3, p.392-995. 2007. Disponível em: http://dx.doi.org/10.1590/S0102-05362007000300014.

LIMA, R. L. S.; SEVERINO, L. S.; SILVA, M. I.de L.; JERÔNIMO, J. F.; VALE, L. S.; BELTRÃO, E.de M. Substratos para produção de mudas de mamoneira compostos por misturas de cinco fontes de matéria orgânica. Ciência Agrotécnica, v.30, n.3, p.474-479, 2006. Disponível em: http://dx.doi.org/10.1590/S141370542006000300013.

MEDEIROS, D.C.; AZEVEDO, C.M.S.B.; MARQUES, L.F.; SOUSA, R.A.; OLIVEIRA, C.J. Qualidade de mudas de tomate em função do substrato e irrigação com efluente de piscicultura. Revista Brasileira de Agroecologia, v. 8, n. 2, 2013. ISSN 19809735. Disponível em: <http://revistas.abaagroecologia.org.br/index.php/rbagroecologia/article/view/10389>. Acesso em: 23 mar. 2018.

MOREIRA, M. A.; DANTAS, F. M.; BIANCHINI, F. G.; VIÉGAS, P. R. A. Produção de mudas de berinjela com uso de pó de coco. Revista Brasileira de Produtos Agroindustriais, v.12, n.2, p.163-170, 2010. Disponível em:< https://docplayer.com.br/15522224-Producao-de-mudas-de-berinjela-com-uso-de-pode-coco.html > Acesso em 21 jun. 2018.

NASCIMENTO, A. F.; PIRES, F. R.; CZEPAK, M. P.; FERNANDES, A. A.; RODRIGUES, J. de. O. Caracterização de vermicomposto produzido com palha de café e esterco bovino. Revista Caatinga, v. 28, n. 4, p. 1 - 9, 2015. Disponível em: http://dx.doi.org/10.1590/1983-21252015v28n401rc.

SABIO, R. P.; PAGLIUCA, L. G.; JULIÃO, L.; DELEO, J. P. B.; BOTEON, M. Anuário Hortifruti Brasil Retrospectiva 2015 \& Perspectiva 2016. Hortifruticultura Brasileira, 6p, 2016. Disponível em: http://www.hfbrasil.org.br/br/revista/acessar/capa/ahortifruti-brasil-vai-para-a-rede-em-2016.aspx> Acesso em: 08 jul. 2018.

SANTOS, B. L. dos.; CASTAGNARA, D. D.; BULEGON, G. L.; ZOZ, T.; OLIVEIRA, R. S. P. de.; GONÇALVES JÚNIOR, C. A.; NERES, A. M. Substituição da adubação nitrogenada mineral pela cama de frango na sucessão aveia/milho. Bioscience Journal, v. 30, supplement 1, p. 272-281, 2014. Disponível em: < http://www.seer.ufu.br/index.php/biosciencejournal/article/view/17979/14538> Acesso em: 08 jul. 2018.

SANTOS, S. V. dos.; ALVES, M. R.; MELO, F. G. de.; FILHO, M. S. Uso de diferentes substratos na produção de mudas de cupuaçuzeiro. Enciclopédia Biosfera, v.10, n.18; p. 2014. Disponível em: < http://www.conhecer.org.br/enciclop/2014a/AGRARIAS/Uso\%20de\%20diferentes.pdf $>$ Acessado em: 28 jun. 2018. 
SEDIYAMA, N. A. M.; SANTOS, C. I. dos.; LIMA, C. P. de. Cultivo de hortaliças no sistema orgânico. Revista Ceres, v. 61, Suplemento, p. 829-837, 2014. Disponível em: http://dx.doi.org/10.1590/0034-737x201461000008.

SILVA, F. de A. S. e.; AZEVEDO, C. A. V. de. The Assistat Software Version 7.7 and its use in the analysis of experimental data. Afr. Journal Agricultural Research, v.11, n. 39, p.3733-3740, 2016. Disponível em: DOI: 10.5897/AJAR2016.11522.

STEFFEN, G. P. K.; ANTONIOLLI, Z. I.; STEFFEN, R. B.; MACHADO, R. G. Casca de arroz e esterco bovino como substratos para a multiplicação de minhocas e produção de mudas de tomate e alface. Acta Zoológica Mexicana, Número Especial 2, p.333-34, 2010. Disponível em: Doi: 10.21829/azm.2010.262898.

SUGUINO, E.; MARTINS, A. N.; MINAMI, K. E. I. G. O.; NARITA, N. O. B. U. Y. O. S. H. I.; PERDONA, M. J. Efeito da porosidade do substrato casca de pinus no desenvolvimento de mudas de grumixameira. Revista Brasileira de Fruticultura, p.643-648, 2001. Disponível em: http://dx.doi.org/10.1590/S010029452011000500089.

TRAZZI, P. A.; CALDEIRA, M. V. W.; PASSOS, R. R.; GONÇALVES, E. O. Substratos de origem orgânica para produção de mudas de teca (Tectona grandis Linn. F.). Ciência Florestal, v.23, n.3, p.401-409, 2013. Disponível em: http://dx.doi.org/10.5902/1980509810551. 